\title{
Ground-based GPS remote sensing for precipitable water vapor: A case study of the heat-island effect in Taipei
}

\author{
Ta-Kang Yeh *, Shih-Liang Chan, Hsuan-Chang Shih, and Kuan-Chen Su
}

Department of Real Estate and Built Environment, National Taipei University, New Taipei City, Taiwan

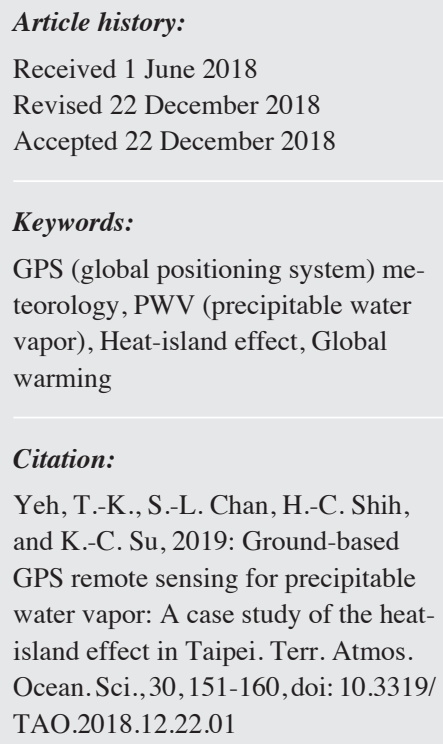

Received 1 June 2018

Revised 22 December 2018

Accepted 22 December 2018

Keywords:

GPS (global positioning system) meteorology, PWV (precipitable water vapor), Heat-island effect, Global warming

Citation:

Yeh, T.-K., S.-L. Chan, H.-C. Shih, and K.-C. Su, 2019: Ground-based GPS remote sensing for precipitable water vapor: A case study of the heatisland effect in Taipei. Terr. Atmos. Ocean. Sci., 30, 151-160, doi: 10.3319/ TAO.2018.12.22.01

\begin{abstract}
It is known that there are severe heat-island effects in the urbanized area such as Taipei and that temperature increases are causing hydrological change. The city continues to develop, so it is urgent that the region creates early warning methods. In this study, we observed the influence of the heat-island effect on temperature, precipitable water vapor (PWV), and rainfall in a suburb in Taipei and confirmed that the urban area had a rising temperature trend during the period from 2006 - 2014, approximately 0.7 degrees higher than that in the suburb, which decreased by 1.1 degrees. The average PWV increased by approximately $6.7 \mathrm{~mm}$ and the cumulative rainfall increased approximately $54.7 \mathrm{~mm}$. Two other high-temperature areas are in the development zone and in the northern mountainous area, which is lower in temperature, and a heat-island effect is obvious. Rainfall is greatest in the southern mountainous areas in summer. Due to wind direction in the winter, rain falls in the northeastern region of the windward side. Our results also show that there is a significant urban heat-island effect in the Taipei region and that PWV and rainfall are increasing in the urban area with global warming.
\end{abstract}

\section{INTRODUCTION}

Global warming is a major environmental concern, causing extreme weather and serious impacts on ecosystems. Since 1970, the rapid growth of industrial and commercial activities in Taiwan has helped feed its urbanization and led to most of the population living in urban areas. Taipei and the New Taipei are the two most populated cities in Taiwan, with an aggregate population of six million during 2006 - 2014. These urban areas are significantly warmer than their surrounding rural areas; hence, understanding the relationship between population growth and changes in the environment is very important for forecast warnings.

Past studies have demonstrated the connection between urbanization and temperature increase (Van Hove et al. 2015). Urban scale is an important factor in the intensity of the heat-island effect (Karl et al. 1988) and yields a temperature difference between the metropolitan and rural areas (Lai and Cheng 2010). Changes in rainfall caused by urbanization were discussed in Huang et al. (2015) and Yeh et al. (2016); there is an obvious relation to the heat generated from the urban area (Shepherd et al. 2002).

Human activities and urban development have led to regional temperature warming. Evapotranspiration due to the temperature change has a direct relation to the increase or decrease in PWV and rainfall, with subsequent weather changes and increased frequency of disaster, a threat to the natural environment and to human property. Detection of meteorological change requires lengthy monitoring. Following past studies of the meteorology of Taiwan (Yeh et al. 2016, 2018), we aim to analyze the trends of temperature, PWV, and rainfall in Taipei City. It will be beneficial to identify the turning point or divergence of the meteorological change, especially there have been no discussions on the PWV variations under heat-island effect. To reach this aim, the literature review are divided in two parts as follows:

\footnotetext{
* Corresponding author

E-mail:bigsteel@mail.ntpu.edu.tw
}

\subsection{Temperature Trends}

Urban development increases anthropogenic emissions, 
and more and more evidence demonstrates the warming trend of the global average temperature. The human activity is very relevant, and the warming phenomenon can be observed around the world. Warming intensity varies by region (Johns et al. 2006). The Fifth Assessment Report of the Intergovernmental Panel on Climate Change (IPCC 2013), the panel jointly established by the United Nations World Meteorological Organization (WMO) and the United Nations Environment Program (UNCP), indicates that human activity is very likely the most important factor for warming since the mid-20th century (95\% confidence level).

In 1880 - 2012, greenhouse gases from the use of fossil fuels and land reclamation by humans increased the global average temperature by $0.85^{\circ} \mathrm{C}$ (IPCC 2013). In the past 30 years, the surface temperature of Earth is continuing to warm, and those 30 years have been the warmest in nearly a thousand years. If greenhouse gas emissions cannot be substantially reduced, the average surface temperature in this century may rise by $4.8^{\circ} \mathrm{C}$. Taiwan is listed in the high-risk group for impacts of climate change.

Shiu et al. (2009) showed that the average temperature in Taiwan has a warming trend, and the increase is approximately twice as high as that of the Northern Hemisphere as a whole. Hsu et al. (2011) indicated that the warming trend in Taiwan in $1980-2009$ is $0.29^{\circ} \mathrm{C}$ over 10 years. This value is nearly twice the global trend of the last 100 years and larger than those from neighboring Japan and mainland China. The study also found that Taiwan's annual average temperature changes for 100,50 , and 30 years have a significant upward trend, and it is estimated that Taiwan's temperature will rise by $2-3^{\circ} \mathrm{C}$ by the end of this century, suggesting a serious impact on Taiwan's meteorology. Lai and Cheng (2010) analyzed the temperature data from 1897 - 2005 and found that the annual maximum temperature, annual mean minimum temperature and the days with temperature greater than $30^{\circ} \mathrm{C}$ in Taiwan increased significantly in most areas; further, they show that human activities seriously affected the temperature changes in urban areas.

The rapid urban growth will have many serious environmental effects, including the heat-island phenomenon, which has become an important issue in the human environment and global climate change. Past studies have shown that most of the metropolitan areas in Taiwan experience urban heat-island effects. Bai et al. (2011) analyzed the temperature data of Taipei for 28 years and found that the impact of urbanization led to significant increases in the average temperature and minimum temperature in Taipei, particularly after the rapid urbanization of Taipei in 1967 and warming phenomena in urban areas in 1985. In Taipei City, the correlation between urbanization and maximum temperature change is not significant, but that with the summer minimum temperature increase is significant. Lai and Cheng (2010) also found during the study period that economic development in Taiwan during the period from 1962
- 2005, leading to the increase in the maximum temperature and minimum temperature of major cities. There is a positive relationship between the temperature change and the degree of urban development. The statistical results show that human activities seriously affect the temperature difference of the area.

The IPCC report (2013) indicated that the surface temperature is rising everywhere, on a longer time scale and a larger spatial scale. In the future, there will be more hot days and fewer cold days. The scientific community has 90\% confidence that heat waves will occur more often and with extended durations but that the occasional cold winter, amid warmer winters, will still exist. Wallace et al. (2014) also observed that the most snow and the lowest temperature in history occurred in the urban areas of central and eastern America, i.e., Chicago and New York. Van Hove et al. (2015) observed the Rotterdam urban area's strongest heat effect in summer. This results in many hours of discomfort (physiologically equivalent temperature $>23^{\circ} \mathrm{C}$ ). Their results indicate that daytime comfort hours appear to be mainly related to differences in wind velocity. The much lower wind velocity in the urban areas leads to the accumulation of heat. After sunset, the urban heat-island effect plays a more prominent role, and hence, the number of comfort hours is more related to the urban characteristics. Further, vegetation, open ground and large water bodies are helpful in reducing urban heating. Similarly, Georgescu et al. (2013) found that the summer average temperature has increased by $4^{\circ} \mathrm{C}$ in Sun Corridor, Arizona, over the past 45 years.

The same heat island effect has also occurred in metropolitan areas in other countries. According to Yamashita (1996), the increased temperature due to the heat-island effect can reach $5^{\circ} \mathrm{C}$ in the Tokyo metropolitan area on sunny days. Oh et al. (2004) analyzed the 10-year temperature data in Korea and showed a rapid rise of $1.39^{\circ} \mathrm{C}$ in the Seoul metropolitan area and $0.43^{\circ} \mathrm{C}$ in rural areas. Van Hove et al. (2015) analyzed the temperature difference between Rotterdam and surrounding rural areas from 2010 - 2012. The highest heat-island intensity was found in densely populated, built-up cities in summer. The heat-island effect is an important concern for most metropolitan areas around the world.

\subsection{Rainfall Trends}

In addition to temperature, the change in rainfall is also a focus of changes in weather. The global warming will affect the water cycle and will result in changes to rainfall type and distribution (IPCC 2007). However, the relationship between rainfall and temperature is complex. The IPCC's Fifth Assessment Report (2013) noted that the global water cycle changes caused by warming in the twenty-first century were not consistent across the world. Between wet and dry areas, as well as between wet and dry season, the 
difference in precipitation will be further widened. Humid areas will become increasingly moist and dry areas drier, but there will be regional exceptions.

According to IPCC (2013), the water cycle change from the next few decades to the end of this century will be similar on the global scale. However, regional changes are significantly influenced by natural internal variables and aerosol emissions from human activity. The average annual precipitation in the middle and high latitudes and the equatorial Pacific is likely to increase by the end of this century. Average precipitation will decline in many mid-latitude and subtropical dry areas, and in rainier areas, it is likely to rise. In addition, the study of changes in extreme weather and climate events indicates that as the global average surface temperature increases, extreme rain events in most mid-latitude and tropical rainy regions are likely to show higher intensity and frequency by the end of this century.

Chen et al. (2008) indicated that the rainfall in Taiwan is affected by various weather systems and performs differently in different seasons: spring rainfall, the meiyu season in May to June, and the typhoon season in summer. Hsu et al. (2011) pointed out that the number of days of rainfall in Taiwan has decreased, but rainfall intensity has increased, and the dry and wet season have become more obvious, a phenomenon similar to the global trend. According to weather model simulations, the average winter rainfall in Taiwan decreases $3-22 \%$ with continuous warming. The model also estimates that summer rainfall increases $2-26 \%$, though the authors emphasize that due to uncertainty regarding precipitation, simulation results can be unreliable.

Shepherd (2005) showed that urban high-rise buildings increase surface roughness. The near-surface airflow decelerates through the city and forms a convergence at the lower reaches of the city. The impact of the urban heat island on precipitation has attracted the attention of many scholars in recent years. Chen et al. (2007) studied the urbanization of the Taipei Basin from 1960 - 2005, and found that in the past 45 years, the number of thunderstorms has increased by $70 \%$ and the summer rainfall by $80 \%$. The observed data show that the heat island has affected the occurrence of afternoon thunderstorms in the Taipei Basin. Lin et al. (2008) pointed out that the convective system, which should have caused precipitation in the mountainous area, is faster in the suburbs than in the urban area, which enhances the convective system so that the precipitation change occurs earlier in lower winds. Huang et al. (2015) also found that atmospheric changes altered in the Taiwan afternoons of 1961 - 2012. Other countries, show similar results in rainfall change. Bornstein and Lin (2000) analyzed six precipitation events in the Atlanta area and found that the heat-island effect caused strong thermal convection. Shepherd et al. (2002) used TRMM satellite data to find that the monthly precipitation in the suburban area has increased by $28 \%$ and that there is a slight increase in the urban area of the southern US city.

\section{DATA AND METHODOLOGY}

Three types of data were collected in this study from 2006 - 2014: GPS measurements, temperature, and rainfall data. Thirty-second sample rate measurements from 15 GPS stations and hourly recorded temperature and precipitation data from 29 weather stations were provided by the Central Weather Bureau in Taiwan. Figure 1 shows the station locations and a topographic map of Taipei City. The orange and blue stars show the urban and suburb stations for the GPS and rainfall, respectively. The orange and blue circles present the urban and suburb stations for the temperature, respectively. The methods we divide the urban and suburb stations are based on the map of land use division. We analyzed the land use status around $1 \mathrm{~km}$ of the stations, when the building area of the station is larger than $50 \%$, the station is divided into urban station.

Regarding data processing of GPS measurements, the Bernese 5.0 software (Dach et al. 2007) was used to process the GPS data. The Zenithal Wet Delay (ZWD) data were determined based on the assumption that the ground point coordinates were fixed using the 30-days average. During the differential calculation process, the satellite orbit and clock errors were corrected with the IGS precise ephemeris.
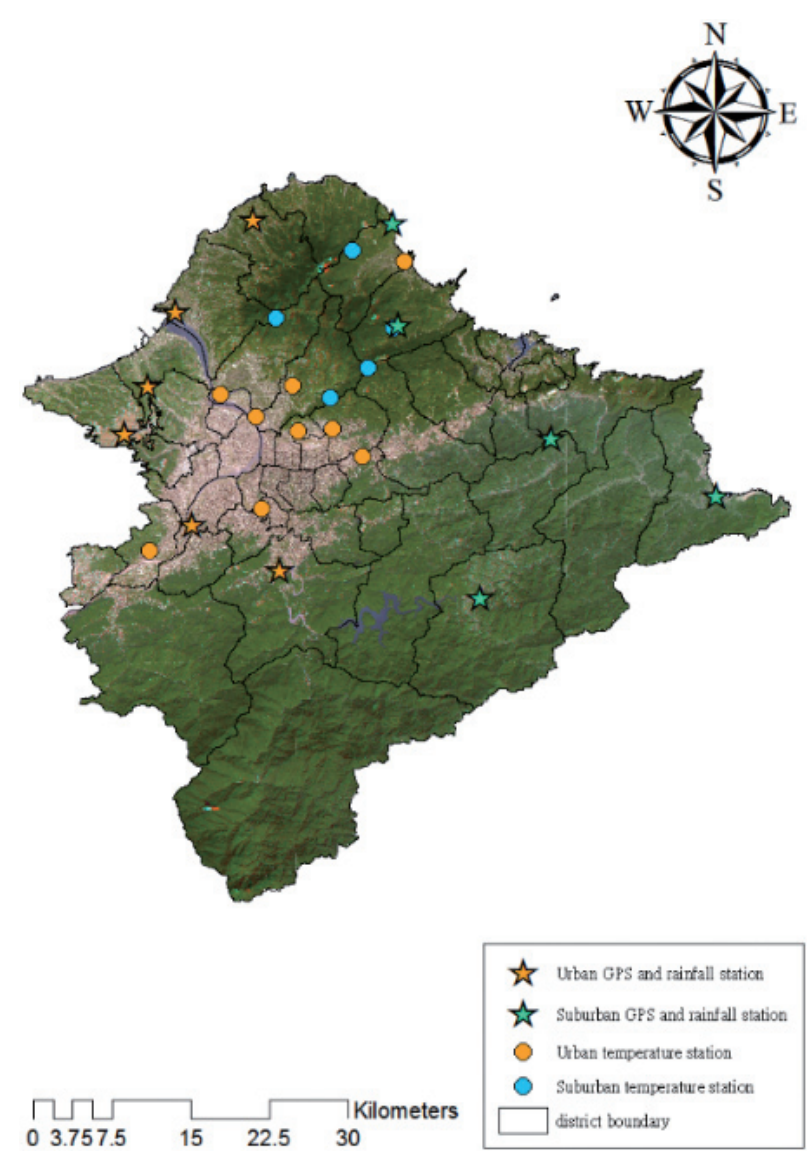

Fig. 1. Station location and topographic map of Taipei City. 
In addition, the ionosphere delay error was eliminated with the L3 linear combination. Moreover, to increase the accuracy of the ZWD calculation, an ocean tide loading correction was applied and the NAO.99b model was used to obtain the optimal correction effect (Chung et al. 2016). To avoid eliminating the desired ZWD when eliminating the common error with a differential method, we used the long baseline static relative positioning method to ensure that the obtained ZWD was the absolute value (Yeh et al. 2014). In this study, the TSKB of Japan was chosen as the main station because it produced the best result. At distances of more than $2000 \mathrm{~km}$, the atmospheric status between the two locations is assumed to be uncorrelated. By increasing the baseline distance between the main station and the calculation station, the atmospheric information can be preserved during the differential calculation. Furthermore, due to the accuracy of the data and the comprehensive error correction, the output frequency of the ZWD was once per hour and 24 times per day per station. Thus, the temporal resolution of the GPS-deduced ZWD was $1 \mathrm{hr}$, which was easier to compare with the temperature and rainfall data.

To convert the ZWD data to PWV data, the relationship between the ZWD $\left(S_{W}\right)$ and PWV $\left(P_{W}\right)$ based on the definition of precipitable water vapor is as follows:

$P_{W}=\Pi \times S_{W}$

where $\Pi$ is the scale factor. The scale factor can be calculated as follows (Bevis et al. 1994):

$\Pi^{-1}=10^{-6}\left[\rho R_{w}\left(k_{3} / T_{m}+k_{2}^{\prime}\right)\right]$

where $k_{2}$ and $k_{3}$ are the experimental constants for atmospheric refraction, and $k_{2}=64.79 \mathrm{~K} \mathrm{hPa}^{-1}, k_{3}=3.766 \times$ $10^{5} \mathrm{~K}^{2} \mathrm{hPa}^{-1}$, and $k_{2}^{\prime}=k_{2}-k_{1} M_{w} / M_{d}=16.52 \mathrm{~K} \mathrm{hPa}^{-1}$. The molar mass of the water vapor $\left(M_{w}\right)$ is $18.015 \mathrm{~g} \mathrm{~mol}^{-1}$, and $R_{w}=R / M_{w}=461.524 \mathrm{~J} \mathrm{~kg} \cdot \mathrm{K}^{-1}$. The scale factor $\Pi$ is related to the temperature and changes in latitude, station height, season, and the weather. Therefore, the method used to determine the temperature is very important. In 1994, Bevis et al. (1994) revealed the following linear relationship between the weighted average temperature $T_{m}$ and the surface temperature $T_{s}: T_{m}=70.2+0.72 T_{s}$. In this study, the Bevis's equation was adopted to convert the ZWD to PWV.

\section{RESULTS}

\subsection{Variations of Temperature from 2006 - 2014 in Taipei}

The time series of the average temperature at Taipei's metropolitan area and suburbs from 2006 - 2014 are show in Figs. 2 and 3 . The average urban and suburban temperatures in summer are 29.2 and $27.7^{\circ} \mathrm{C}$, respectively. In winter, the averages are $17.1^{\circ} \mathrm{C}$ in the urban area and $15.8^{\circ} \mathrm{C}$ in the suburb. Therefore, the average temperature differences are $1.5^{\circ} \mathrm{C}$ in summer and $1.3^{\circ} \mathrm{C}$ in winter. The results reveal two important points: (1) the urban area is hotter than the suburban area, and (2) the heat effect is particularly significant in the summer. Hence, it is clear that the urban heat-island effect affects the temperature of Taipei. It is not a surprise to find that temperatures are increasing in the urban area; in fact, the temperature difference between the urban and suburban areas will further increase with further urban development (e.g., more buildings, population, and cars).

As background, we assume the temperature trends in the suburbs represent local climate change. The temperature trends in the urban area compound the heat-island effect and further increase warming in summer and decrease cooling in winter. Further, the influence of the urban heating on the temperature is greater than the local climate change. In addition, the temperature trends in the urban and suburban areas both indicate that the summer is hotter and the winter cooler than they were previously. However, greenhouse gases have been increasing steadily in the atmosphere since 1970. The global average surface temperature is also higher than the average for the past 100 years.

The distributions of average temperature in Taipei City in summer and in winter are shown in Fig. 4. The temperature trends in the urban and suburban areas are derived via linear analysis of the time series. The summer average temperature has increased by $0.7^{\circ} \mathrm{C}$ at the urban area and by $0.6^{\circ} \mathrm{C}$ in the suburban area in the past nine years. The winter average temperature has dropped by 0.9 and $1.2^{\circ} \mathrm{C}$ in the urban and the suburban areas, respectively. In the face of global warming, average summer and winter temperatures are expected to increase gradually, but this tendency may not be exhibited everywhere on local scales or on a short time scale. Areas affected by multiple weather systems, such as Taiwan, may exhibit different tendencies with respect to temperature. Therefore, an aggregation of individual studies focusing on different weather features is necessary to investigate long-term climate change in specific regions. In this study, the short data record is not sufficient to establish climate change's impact on temperature. However, the average temperatures in the urban and suburban areas demonstrate an obvious heat-island effect. The temperature trend may also serve as a warning for urban residents and the city government.

\subsection{Variations of PWV and Rainfall from 2006 - 2014 in Taipei}

The time resolution of the temperature, PWV and rainfall data are all in one hour in this study. Because more than $80 \%$ hourly rainfall is zero, if we used the average rainfall, the value will be highly underestimated. It will be a problem 


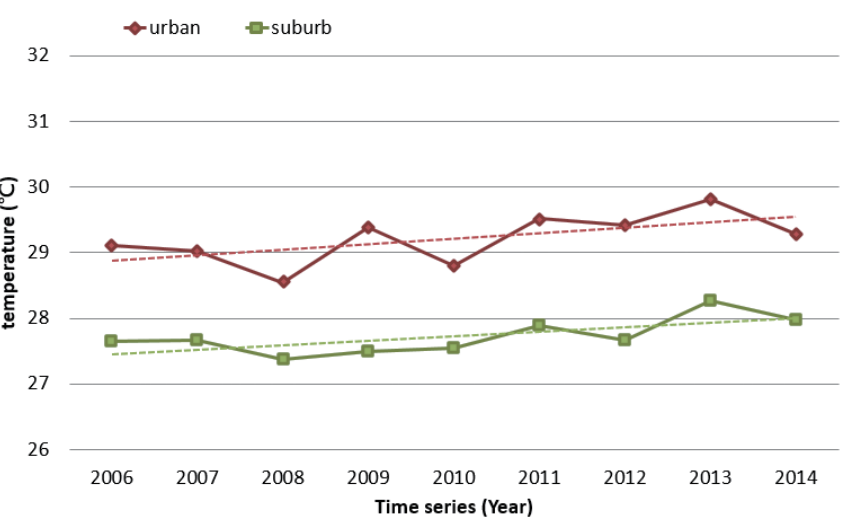

Fig. 2. Average temperature of Taipei City in summer from 2006 - 2014.

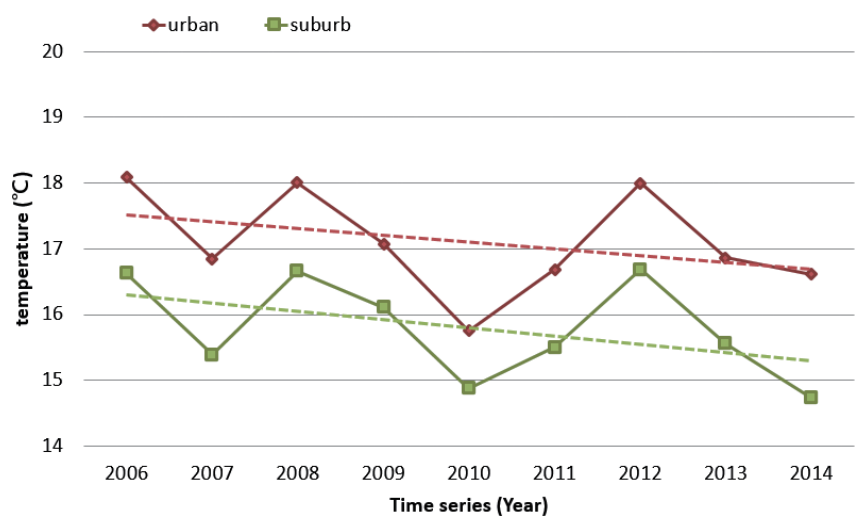

Fig. 3. Average temperature of Taipei City in winter from 2006 - 2014.

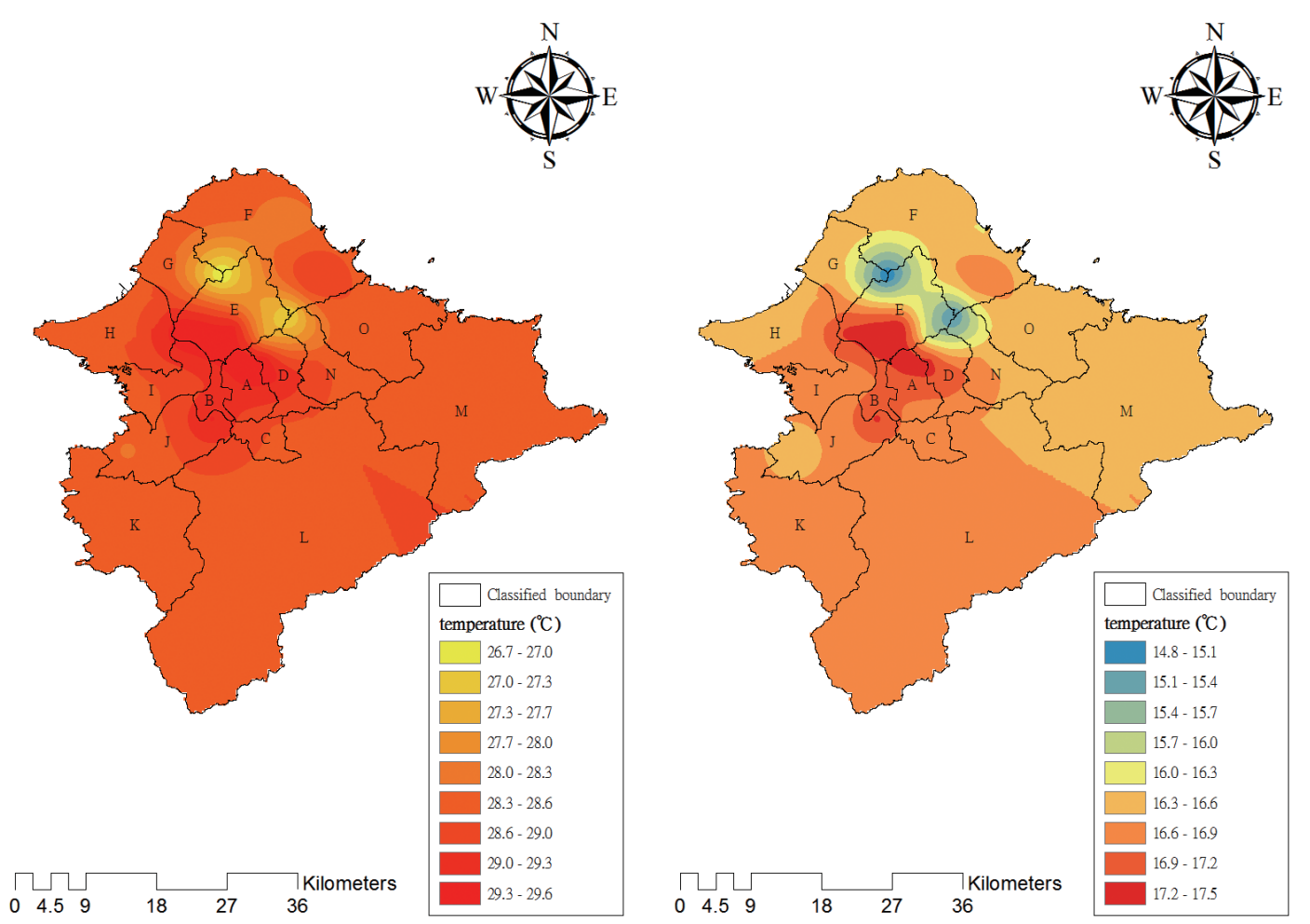

Fig. 4. Distribution of average temperature of Taipei City in summer (left) and in winter (right) from 2006 - 2014. 
if we compare the temperature, PWV and rainfall data per hour directly. Therefore, the average temperature and PWV data are employed but the cumulative rainfall per month is used for the following analysis.

The time series of the average PWV and cumulative rainfall in Taipei's metropolitan area and suburbs from 2006 - 2014 are show in Figs. 5 and 6. Under the influence of the heat-island effect, this study continues to study the performance of its precipitation over the past nine years. In the summer, the average PWV in the urban area is 52.8 and $52.0 \mathrm{~mm}$ in the suburban area; in winter, the average PWV in the urban area is 31.0 and $31.2 \mathrm{~mm}$ in the suburban area. The PWV in summer is clearly higher than that in winter. The PWV difference between the urban and suburban areas in summer is $0.8 \mathrm{~mm}$ and is higher in the urban area than in the suburban area in summer. On the other hand, the PWV is almost the same between them in winter. Since winter is cool, evaporation is less active; therefore, the effect on the amount of PWV is not strong, resulting in the insignificant difference between the urban and suburban areas. When the temperature rises, evapotranspiration is substantial, and the amount of PWV changes strongly. Therefore, the difference in PWV in the urban and suburban areas in summer is significantly different from that in winter. The temperature of the urban area due to the heat-island effect is relatively high, and the total amount of PWV in the urban area is higher than that in suburban area.

We also studied the PWV and rainfall trends in summer and winter to discover their impacts on the inhabitants of Taipei. After calculating the change of temperature in the urban and suburban areas during the past nine years, the average temperature, PWV and cumulative rainfall data were integrated into Table 1 . The upper row is the average value of nine years, and the lower row is the increasing or decreasing value in summer and in winter. When we calculated the increasing (or decreasing) value, the slope was obtained by linear regression using nine-year data. This slope showed the increasing value per year. Because we would like to present the nine-year increasing value, the above slope is multiplied by nine, to obtain the increasing temperature, PWV, and cumulative rainfall in the urban and suburban areas of the Taipei region during the nine years.

According to Table 1, during the summer, the amount of PWV in the urban area increased by $7.8 \mathrm{~mm}$ in nine years and by $8.4 \mathrm{~mm}$ in the suburbs. In winter, the amount of PWV in urban areas increased by $5.9 \mathrm{~mm}$, and by $4.8 \mathrm{~mm}$ in the suburbs. In the past nine years, the PWV in both urban and suburban areas has increased. The increase of PWV in the suburbs in summer is higher than in winter. Moreover, the increase in PWV in urban areas is generally higher than in suburban areas. Under global warming, the rising trend of temperature synchronously affects the overall increase in PWV. Due to the heat-island effect, temperature and PWV are higher in the urban area and lower in the suburban area.
The differences in average PWV and cumulative rainfall between urban and suburban areas are shown in Figs. 7 and 8. The cumulative rainfall is approximately $255.2 \mathrm{~mm}$ in the urban area and $217.3 \mathrm{~mm}$ in the suburban area in summer. In winter, the cumulative rainfall is approximately $202.5 \mathrm{~mm}$ in the urban area and $520.9 \mathrm{~mm}$ in the suburban area. Summer rainfall is usually higher than that in winter, except for the influence of the Northeast Monsoon in winter. Because all the suburb rainfall stations are located at the Northeast side of Taipei, the rainfall is very large at the windward side in winter. The precipitation recordings at the stations on the windward side show a relatively large amount of rainfall. The difference in rainfall between the urban and suburban areas is $+37.9 \mathrm{~mm}$ (higher in urban area) in summer and $-318.4 \mathrm{~mm}$ (higher in suburban area) in winter.

As global warming has increased PWV, the trend of PWV and rainfall is increasing both in urban and suburban areas. Annual cumulative rainfall in summer increased by $29.5 \mathrm{~mm}$ in the urban area and $93.2 \mathrm{~mm}$ in the suburban area. The annual cumulative rainfall in winter increased by $56.6 \mathrm{~mm}$ in the urban area and $39.5 \mathrm{~mm}$ in the suburban area. Especially in the suburbs in the summer, when warming boosted the increase in PWV, rainfall increased significantly, $42.8 \%$. In the suburbs, the rainfall in the past three years was double that of the previous three years in summer. In Table 1, we can see that there is a slight increase in the amount of PWV and rainfall; for example, in the suburbs in summer, the PWV (+8.4 mm) and the rainfall $(+93.2 \mathrm{~mm})$ increased the most in nine years.

\section{CONCLUSIONS}

This study analyzed the climatic behavior of the Taipei area in urban and suburban areas in winter and summer from 2006 - 2014. It is concluded that the average annual temperature in the urban areas was higher than that in the suburbs in summer or winter, that there were urban heat-island effects in the Taipei area, and that these effects were more significant in summer. Precipitation in the urban area is increasing in summer, rising by approximately $11.6 \%$ (i.e., $29.5 / 255.5$ $\times 100 \%)$ in nine years, which is calculated using nine-year increasing rainfall divided by nine-year average rainfall. Precipitation in the urban area also is increasing in winter, rising approximately $27.9 \%$ (i.e., $56.6 / 202.5 \times 100 \%$ ) in nine years. It can be speculated that global warming and the urban heat-island effect cause the increased precipitation. Thus, it is very likely that rainfall will continue to increase in the future. In the summer, suburbs show the largest increase in precipitation in nine years. While in winter, the cumulative rainfall of suburbs is also the most in nine years.

The correlation coefficient between PWV and precipitation is moderately related in summer, but a smaller correlation coefficient was observed in winter, which can be 


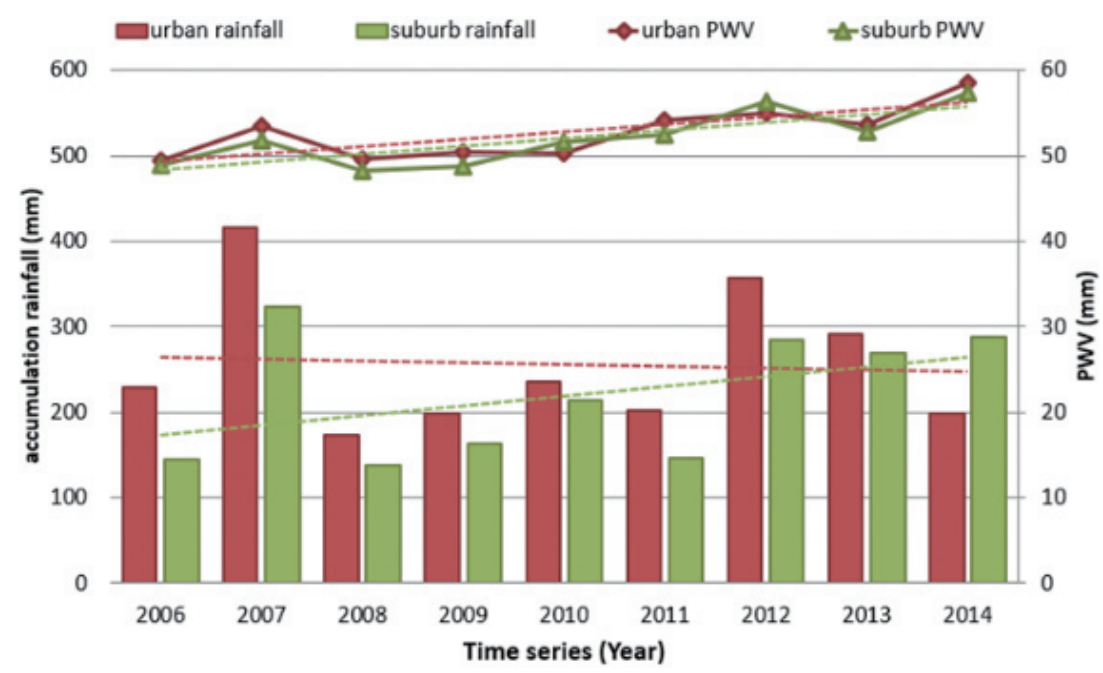

Fig. 5. Average PWV and cumulative rainfall of Taipei City in summer from 2006 - 2014.

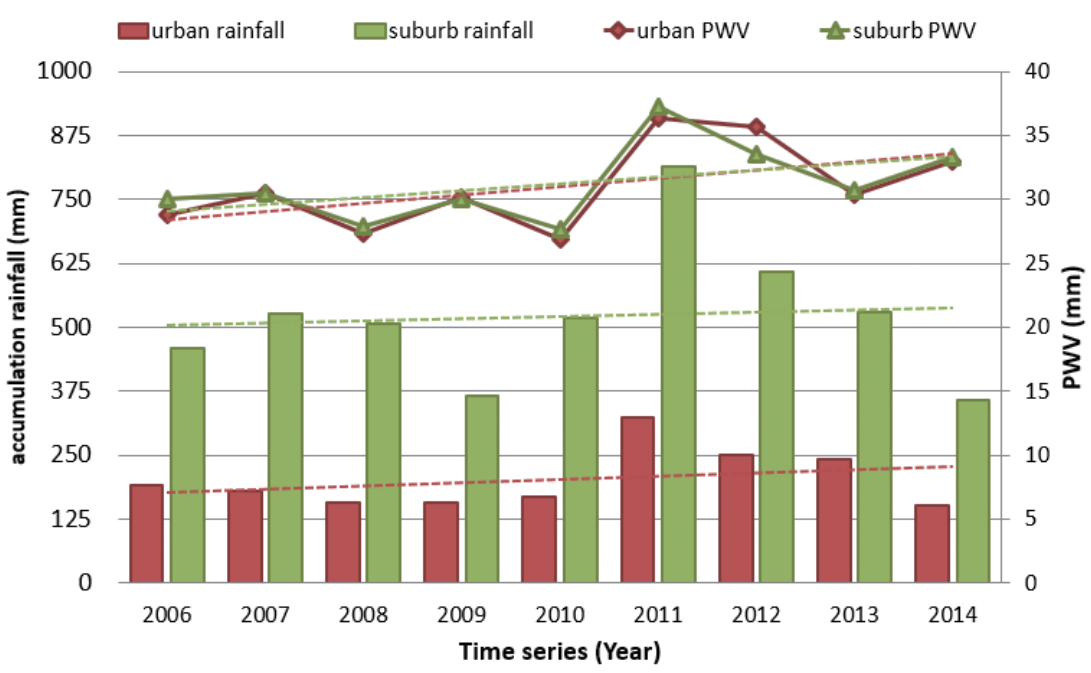

Fig. 6. Average PWV and cumulative rainfall of Taipei City in winter from 2006 - 2014.

Table 1. Trend of temperature, PWV and rainfall from 2006 - 2014. The upper row shows average values, the bottom column the amount of increase.

\begin{tabular}{c|cc|cc|cc}
\hline \multirow{2}{*}{ Zone } & \multicolumn{2}{|c|}{ Temperature $\left({ }^{\circ} \mathbf{C}\right)$} & \multicolumn{2}{c|}{ PWV $(\mathbf{m m})$} & \multicolumn{2}{c}{ Rainfall $(\mathbf{m m})$} \\
\cline { 2 - 7 } & Summer & Winter & Summer & Winter & Summer & Winter \\
\hline \multirow{2}{*}{ Urban } & $29.2 \pm 0.4$ & $17.1 \pm 0.8$ & $52.8 \pm 3.1$ & $31.0 \pm 3.4$ & $255.2 \pm 82.2$ & $202.5 \pm 57.8$ \\
& +0.7 & -0.9 & +7.8 & +5.9 & $+29.5^{*}$ & +56.6 \\
\multirow{3}{*}{ Suburb } & $27.7 \pm 0.3$ & $15.8 \pm 0.8$ & $52.0 \pm 3.0$ & $31.2 \pm 3.0$ & $217.3 \pm 71.4$ & $520.9 \pm 162.9$ \\
& +0.6 & -1.2 & +8.4 & +4.8 & +93.2 & +39.5 \\
\hline
\end{tabular}

Note: *: The rainfall of 2014 is not included. 


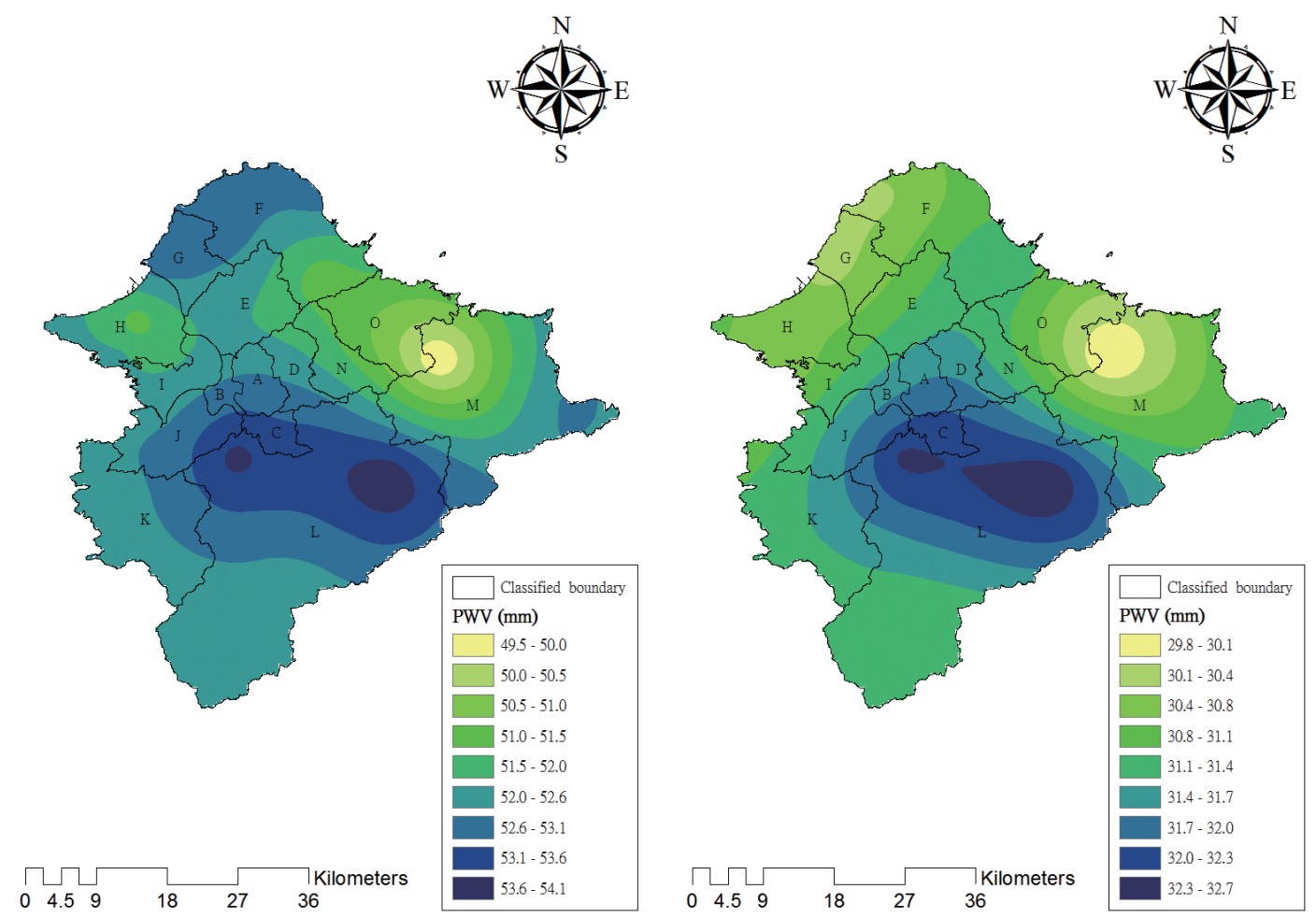

Fig. 7. Distribution of average PWV of Taipei City in summer (left) and in winter (right) from 2006 - 2014.
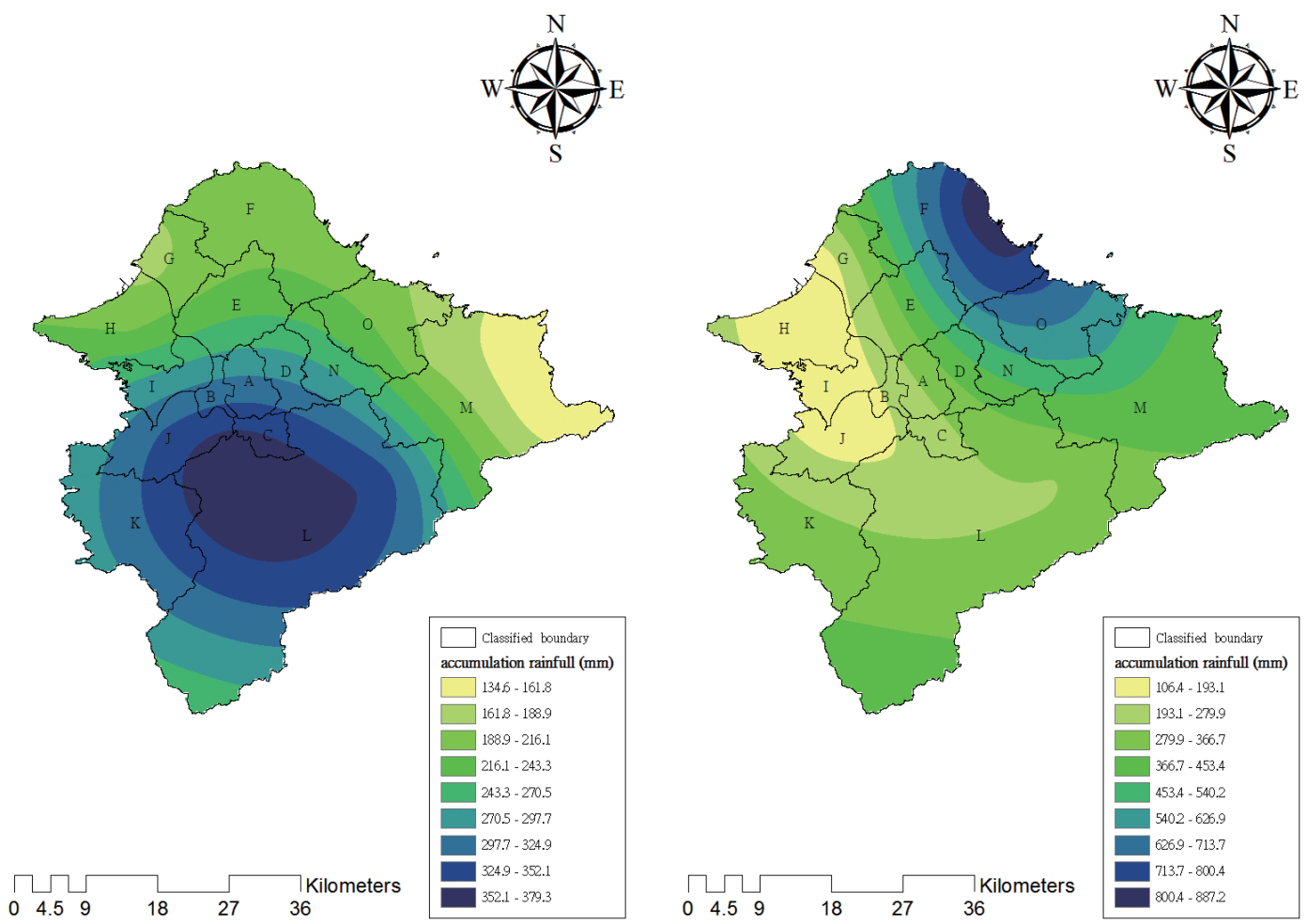

Fig. 8. Distribution of cumulative rainfall of Taipei City in summer (left) and in winter (right) from 2006 - 2014. 
concluded to summer warming and strong evapotranspiration. For the winter cooling, the convection activity is not strong. So the changes of temperature and precipitation are not significant. In addition, the relationship between PWV and rainfall is higher than that between temperature and $\mathrm{PWV}$, the correction of temperature, PWV and rainfall is also determined.

The space distribution of the Taipei area shows that the hot zone is concentrated in the developed area (zones A, B, and D in Fig. 4, please also refer the topographic map in Fig. 1), and in both summer and winter, the urban heatisland phenomenon is obvious. PWV are concentrated in the mountains (zone L), but rainfall caused by other weather systems and geographical conditions, such as wind direction, falls in the windward side: summer concentration in the southwest (zone L) and winter concentration in the northeast (zone F).

The urban growth of Taipei is still in a relatively early phase, the population density is limited, and the suburbs are relatively large. As the population density grows, the suburbs are bound to accelerate development and face the risks associated with climate change, with increased attendant risks. This study has examined the environmental effects of the changes of temperature and PWV in the Greater Taipei area. In the future, it will be necessary to take into account these environmental factors in disaster prevention and planning, to avoid the excessive expansion of the city, and to avoid exacerbating the urban heat-island effect, in order to avoid irreparable damage. Future studies regarding how to reduce the damage to the environment in the new metropolitan area (e.g., increase green space) will be warranted.

\section{REFERENCES}

Bai, Y., J. Y. Juang, and A. Kondoh, 2011: Urban warming and urban heat islands in Taipei, Taiwan. In: Taniguchi, M. (Ed.), Groundwater and Subsurface Environments, Springer, Tokyo, 231-246, doi: 10.1007/978-4431-53904-9_12. [Link]

Bevis, M., S. Businger, S. Chiswell, T. A. Herring, R. A. Anthes, C. Rocken, and R. H. Ware, 1994: GPS meteorology: Mapping zenith wet delays onto precipitable water. J. Appl. Meteorol., 33, 379-386, doi: 10.1175 /1520-0450(1994)033<0379:GMMZWD>2.0.CO;2. [Link]

Bornstein, R. and Q. Lin, 2000: Urban heat islands and summertime convective thunderstorms in Atlanta: Three case studies. Atmos. Environ., 34, 507-516, doi: 10.1016/S1352-2310(99)00374-X. [Link]

Chen, J. M., F. C. Lu, and C. F. Shih, 2008: Decadal oscillation of fall temperature in Taiwan. Terr. Atmos. Ocean. Sci.,19,497-504, doi: 10.3319/TAO.2008.19.5.497(A). [Link]

Chen, T. C., S. Y. Wang, and M. C. Yen, 2007: Enhance- ment of afternoon thunderstorm activity by urbanization in a valley: Taipei. J. Appl. Meteorol. Climatol., 46, 1324-1340, doi: 10.1175/JAM2526.1. [Link]

Chung, Y. D., T. K. Yeh, G. Xu, C. S. Chen, C. Hwang, and H. C. Shih, 2016: GPS height variations affected by ocean tidal loading along the coast of Taiwan. IEEE Sensor. J., 16, 3697-3704, doi: 10.1109/ JSEN.2016.2538325. [Link]

Dach, R., U. Hugentobler, P. Fridez, and M. Meindl, 2007: Bernese GPS Software Version 5.0, User Manual, Astronomical Institute, University of Bern, Bern, Switzerland, $640 \mathrm{pp}$.

Georgescu, M., M. Moustaoui, A. Mahalov, and J. Dudhia, 2013: Summer-time climate impacts of projected megapolitan expansion in Arizona. Nat. Clim. Change, 3, 37-41, doi: 10.1038/nclimate1656. [Link]

Hsu, H. H., C. Chou, Y. C. Wu, M. M. Lu, C. T. Chen, and Y. M. Chen, 2011: Climate Change in Taiwan: Scientific Report 2011 (Summary), National Science Council, Taipei, Taiwan, 67 pp.

Huang, W. R., H. H. Hsu, S. Y. Wang, and J. P. Chen, 2015: Impact of atmospheric changes on the low-frequency variations of convective afternoon rainfall activity over Taiwan. J. Geophys. Res., 120, 8743-8758, doi: 10.1002/2015JD023568. [Link]

IPCC, 2007: Climate Change 2007: Synthesis Report, IPCC, Geneva, Switzerland, 104 pp.

IPCC, 2013: Climate Change 2013: The Physical Science Basis, Cambridge University Press, Cambridge, United Kingdom and New York, NY, USA, 1535 pp.

Johns, T. C., C. F. Durman, H. T. Banks, M. J. Roberts, A. J. McLaren, J. K. Ridley, C. A. Senior, K. D. Williams, A. Jones, G. J. Rickard, S. Cusack, W. J. Ingram, M. Crucifix, D. M. Sexton, M. M. Joshi, B. Dong, H. Spencer, R. S. Hill, J. M. Gregory, A. B. Keen, A. K. Pardaens, J. A. Lowe, A. Bodas-Salcedo, S. Stark, and Y. Searl, 2006: The new Hadley Centre climate model (HadGEM1): Evaluation of coupled simulations. $J$. Climate, 19, 1327-1353, doi: 10.1175/JCLI3712.1. [Link]

Karl, T. R., H. F. Diaz, and G. Kukla, 1988: Urbanization: Its detection and effect in the United States climate record. J. Climate, 1, 1099-1123, doi: 10.1175/1520-044 2(1988)001<1099:UIDAEI>2.0.CO;2. [Link $]$

Lai, L. W. and W. L. Cheng, 2010: Air temperature change due to human activities in Taiwan for the past century. Int. J. Climatol., 30, 432-444, doi: 10.1002/joc.1898. [Link]

Lin, C. Y., F. Chen, J. C. Huang, W. C. Chen, Y. A. Liou, W. N. Chen, and S. C. Liu, 2008: Urban heat island effect and its impact on boundary layer development and land-sea circulation over northern Taiwan. Atmos. Environ., 42, 5635-5649, doi: 10.1016/j.atmosenv.2008.03.015. [Link] 
Oh, S. N., Y. H. Kim, and M. S. Hyun, 2004: Impact of urbanization on climate change in Korea, 1973-2002. Asia-Pacific Journal of Atmospheric Sciences, 40, 725-740.

Shepherd, J. M., 2005: A review of current investigations of urban-induced rainfall and recommendations for the future. Earth Interact., 9, 1-27, doi: 10.1175/EI156.1. [Link]

Shepherd, J. M., H. Pierce, and A. J. Negri, 2002: Rainfall modification by major urban areas: Observations from spaceborne rain radar on the TRMM satellite. J. Appl. Meteorol., 41, 689-701, doi: 10.1175/1520-0450(2002 )041<0689:RMBMUA>2.0.CO;2. [Link]

Shiu, C. J., S. C. Liu, and J. P. Chen, 2009: Diurnally asymmetric trends of temperature, humidity, and precipitation in Taiwan. J. Climate, 22, 5635-5649, doi: 10.1175/2009JCLI2514.1. [Link]

Van Hove, L. W. A., C. M. J. Jacobs, B. G. Heusinkveld, J. A.Elbers, B.L. Van Driel, and A. A. M. Holtslag, 2015: Temporal and spatial variability of urban heat island and thermal comfort within the Rotterdam agglomeration. Build. Environ., 83, 91-103, doi: 10.1016/j.buildenv.2014.08.029. [Link]

Wallace, J. M., I. M. Held, D. W. J. Thompson, K. E. Tren- berth, and J. E. Walsh, 2014: Global warming and winter weather. Science, 343, 729-730, doi: 10.1126/ science.343.6172.729. [Link]

Yamashita, S., 1996: Detailed structure of heat island phenomena from moving observations from electric TRAM-CARS in metropolitan Tokyo. Atmos. Environ., 30, 429-435, doi: 10.1016/1352-2310(95)000100 . [Link]

Yeh, T. K., J. S. Hong, C. S. Wang, T. Y. Hsiao, and C. T. Fong, 2014: Applying the water vapor radiometer to verify the precipitable water vapor measured by GPS. Terr. Atmos. Ocean. Sci., 25, 189-201, doi: 10.3319/ TAO.2013.10.14.01(A). [Link]

Yeh, T. K., J. S. Hong, C. S. Wang, C. H. Chen, K. H. Chen, and C. T. Fong, 2016: Determining the precipitable water vapor with ground-based GPS and comparing its yearly variation to rainfall over Taiwan. Adv. Space Res., 57, 2496-2507, doi: 10.1016/j.asr.2016.04.002. [Link]

Yeh, T. K., H. C. Shih, C. S. Wang, S. Choy, C. H. Chen, and J. S. Hong, 2018: Determining the precipitable water vapor thresholds under different rainfall strengths in Taiwan. Adv. Space Res., 61, 941-950, doi: 10.1016/j. asr.2017.11.002. [Link] 